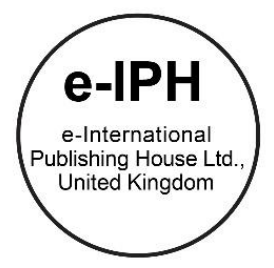

\title{
Predictors of Quality of Life in Individuals Seeking Infertility Treatment: a Malaysian FertiQoL Study
}

\author{
Farnaza Ariffin 1, Suzanna Daud 2, Ani Amelia Zainuddin 3, Roszaman Ramli 4
}

${ }_{1}^{1}$ Primary Care Medicine, Faculty of Medicine, Universiti Teknologi MARA, 47000 Sungai Buloh Campus, Selangor, Malaysia. 2 Obstetrics \& Gynaecology, Faculty of Medicine, Universiti Teknologi MARA, 47000 Sungai Buloh Campus, Selangor, Malaysia. ${ }^{3}$ Obstetrics \& Gynaecology, Faculty of Medicine, Universiti Kebangsaan Malaysia, 43650 Cheras, Kuala Lumpur, Malaysia. 4 Infertility Centre, Kuliyah of Medicine, International Islamic University Malaysia, 25250 Kuantan, Pahang, Malaysia

\begin{abstract}
Infertility problems can lower the quality of life (QoL). This study aims to predict the factors associated with QoL using the Malaysian FertiQoL. This cross-sectional study was conducted at four fertility clinics in Malaysia. Sociodemographic details and FertiQoL responses were collected. A total of 395 participants were analysed using SPSS v24 with a mean (SD) age of 33.18 (4.45). Respondents were predominantly female (57.2\%) and Malay ethnicity (82.5\%). The core domain means score (SD) was 74.68 (14.35) and consisted of mind-body 77.56 (17.55), emotional 70.26 (18.98), relational 77.32 (17.19) and social 73.56 (15.74). Positive predictors for QoL are Islamic faith, higher income, and general well-being.
\end{abstract}

Keywords: Malay FertiQoL; infertile; predictor,

eISSN: 2398-4287@ 2020. The Authors. Published for AMER ABRA cE-Bsby e-International Publishing House, Ltd., UK. This is an open access article under the CC BYNC-ND license (http://creativecommons.org/licenses/by-nc-nd/4.0). Peer-review under responsibility of AMER (Association of Malaysian Environment-Behaviour Researchers), ABRA (Association of Behavioural Researchers on Asians) and cE-Bs (Centre for Environment-Behaviour Studies), Faculty of Architecture, Planning \& Surveying, Universiti Teknologi MARA, Malaysia.

DOI: https://doi.org/10.21834/ebpj.v5iSI3.2565

\subsection{Introduction}

Infertility affects people from all walks of life. Infertility is the inability to conceive after 12-months of regular unprotected sexual intercourse. The prevalence of infertility in developed countries is between 3.5-16.7\% compared to 6.9-9.3\% in developing countries (Boivin et al., 2007; Boivin and Bunting, 2007). The exact prevalence of infertility in Malaysia is unknown. However, from 1975 until 2010, the fertility rate in the country has declined steadily to less than half (Hanafiah and Jemain, 2013). This decline was attributed to several factors, including improved access to higher education for women, the delay in settling down, or the delay in the first conception (Hanafiah and Jemain, 2013). The psychological impact of infertility may have a long and short-term effect on life satisfaction. However, it is evident that the diagnosis of infertility, the treatment process, and the acceptance of this condition has shown to cause a significant loss in quality of life (QoL) (Aarts et al., 2011; Van den Broeck et al., 2010; Wischmann et al., 2012).

Fertility Quality of Life (FertiQL) was developed in 2011 and has been used to measure QoL in various populations in research and clinics (Karabulut et al., 2013; Hsu et al., 2013; Priangga et al., 2016; Maroufizadeh et al., 2017; Desai and Gundabattula.,2019). The FertiQoL is a self-reported questionnaire designed specifically for those who are infertile. The developers were experts from the

eISSN: 2398-4287C 2020. The Authors. Published for AMER ABRA cE-Bsby e-International Publishing House, Ltd., UK. This is an open access article under the CC BYNC-ND license (http://creativecommons.org/licenses/by-nc-nd/4.0/). Peer-review under responsibility of AMER (Association of Malaysian Environment-Behaviour Researchers), ABRA (Association of Behavioural Researchers on Asians) and cE-Bs (Centre for Environment-Behaviour Studies), Faculty of Architecture, Planning \& Surveying, Universiti Teknologi MARA, Malaysia. DOI: https://doi.org/10.21834/ebpj.v5iSI3.2565 
European Society of Human Reproduction and Embryology (ESHRE) and the American Society of Reproductive Medicine (ASRM). This is the first study conducted using Malaysian FertiQoL.

Researchers have been encouraged to conduct FertiQoL studies in local populations. This is to identify predictors that are associated with higher or lower QoL among infertile individuals. So far, studies have shown that both men and women are psychologically and emotionally affected by infertility, although they may respond to it differently (Slade et al., 2007; Edelmann and Connolly, 2010; Omu and Omu, 2010). These FertiQoL studies found that women have lower QoL in the emotional and mind-body domains as compared to men (Hsu et al., 2013; Haica et al., 2013; Bose and Roy, 2017). Higher educational level and secondary infertility were positively associated with QoL, whereas the prolonged duration of infertility and the desire for psychological support was negatively associated with QoL (Karabulut et al., 2013). Studies have also suggested that QoL among infertile individuals was influenced by cultural and religious factors (Greil et al., 2010; Daniluk and Frances-fischer, 2009). The purpose of this study is to identify the predictors of QoL among infertile individuals using the Malaysian FertiQoL.

\subsection{Method}

This cross-sectional study involved infertile individuals seeking treatment at four public infertility clinics in Malaysia. The determining factor for site feasibility was the willingness of the infertility centres to participate in the study. Data collection was from February 2017 until December 2017. All patients who attended the clinic on data collection day were invited and explained about this study. Inclusion criteria were Malaysian residents, men and women aged more than 18 years old, and diagnosed with primary or secondary infertility. Exclusion criteria were those unable to understand or read the Malay language. Patients who fulfilled the inclusion and exclusion criteria and agreed to participate signed a consent form. They were given the questionnaire to answer. The researcher was available on site for any questions or feedback from the participants, but the researcher was not allowed to aid participants or influence their responses. The researcher collected and checked the questionnaires.

The questionnaire had two parts. The first part was for sociodemographic details that included age, gender, race, religion, education level, income, smoking history, previous children, previous infertility counselling, past infertility treatment, and sexual activity per week. The second part was the Malaysian FertiQoL. The FertiQoL is successfully used by researchers from all over the world due to its accessibility and a robust translation process by the original developers (Donarelli et al., 2016). It has quickly become a gold standard for measuring QoL in infertile individuals (Donarelli et al., 2016). The FertiQoL has two general health and well-being perception questions and is divided into two parts, The Core FertiQoL, and the Treatment FertiQoL. The Treatment FertiQoL has two domains: environment and tolerability. The Core FertiQoL measures four domains: mind-body, emotional, relational, and social (Boivin et al., 2011). The mind-body measures the impact of infertility on physical health such as pain or fatigue. The emotional measures the impact of infertility on an individual's emotions such as sadness, grief, and resentment. The relational measures the impact of infertility on the marital partnership such as communication, affection, and sexual relationship. The social measures the effects of infertility on the social aspect such as social inclusion, and support from family and friends (Donarelli et al., 2016).

The sample size calculation used the PS software version 3.0 that recommended a minimal sample of 385 with a $5 \%$ margin error and a 95\% confidence level. Statistical analysis data was analysed using SPSS v24. The Malaysian FertiQoL was validated with good internal consistency and high reliability and was discussed in a separate paper (Ariffin et al., 2020). The analysis used were descriptive, Independent T-test, and Logistic Regression to identify the relationship between factors and FertiQoL scores, and the predictors for good QoL. Ethical approval was obtained from the University Ethics Committee.

\subsection{Results}

A total of 417 participant's answers were collected, and 22 excluded due to incomplete or missing data. The final sample analysed was 395 participants with a mean age of $33.18 \pm 4.45 \mathrm{SD}$.

Table 1: Demographic details of participants according to categories with frequency $(\mathrm{n})$ and percentage $(\%)$.

\begin{tabular}{lll} 
Demographic factors & Categories & Frequency (Percentage) \\
\hline Age range & $<30$ & $74(18.7 \%)$ \\
& $30-39$ & $283(71.6 \%)$ \\
& $40-49$ & $25(6.3 \%)$ \\
\hline Sex & $>50$ & $2(5 \%)$ \\
\hline${ }^{*}$ Race & Male & $166(42.8 \%)$ \\
& Female & $226(57.2 \%)$ \\
\hline${ }^{*}$ Religious faith & Malay & $325(82.5 \%)$ \\
& Chinese & $30(7.6 \%)$ \\
& Indian & $30(7.6 \%)$ \\
& Bumiputera (Sabah \& Sarawak) & $9(2.3 \%)$ \\
\hline${ }^{*}$ Education level & Islam & $331(83.8 \%)$ \\
& Buddhist & $22(5.6 \%)$ \\
& Hindu & $30(7.6 \%)$ \\
& Christian & $9(7.6 \%)$ \\
& Atheist & $2(0.5 \%)$ \\
\hline
\end{tabular}




\begin{tabular}{lll} 
& Certificate / Diploma & $120(30.4 \%)$ \\
& Degree & $169(42.8 \%)$ \\
& Masters / PhD & $41(10.4 \%)$ \\
\hline${ }^{*}$ Income & $<1000$ & $25(6.3 \%)$ \\
& $1001-3000$ & $134(33.9 \%)$ \\
& $3001-5000$ & $137(34.7 \%)$ \\
& $5001-10000$ & $73(18.5 \%)$ \\
\hline Smoking & $>10000$ & $9(2.3 \%)$ \\
\hline Previous children & Yes & $66(16.7 \%)$ \\
\hline Years trying for a baby & No & $323(81.8 \%)$ \\
\hline Previously seen by an Infertility Doctor & Yes & $51(12.9 \%)$ \\
\hline Previous infertility procedure & No & $341(86.3 \%)$ \\
\hline Frequency of sexual activity with a partner & $1-2$ years & $73(18.5 \%)$ \\
\hline
\end{tabular}

${ }^{*}$ For analysing association and relationship, these categories were re-coded into two variables. For race: Malay (1), Non-Malay (0); religion: Islam (1), other religions (0); education level: degree and higher (1), diploma and lower (0); income: RM3000 and higher (1), lower than RM3000 (0)

Table 1 shows the demographic details of the participants. There were more females compared to male participants, and the majority were within the 30-39 age group. For each category, the majority were Malays, Islamic faith, and non-smokers. For education, almost half were degree holders. Many participants had income within the RM1000 - RM5000 bracket. Most participants had primary infertility, and the duration of infertility was between $2-5$ years.

Table 2: Descriptive analysis of the Total mean FertiQoL and mean scores for all domains.

\begin{tabular}{lll} 
Domain & Total mean score & SD \\
\hline Mind-body & 77.56 & 17.55 \\
Emotional & 70.26 & 18.98 \\
Relational & 77.32 & 17.20 \\
Social & 73.56 & 15.74 \\
\hline Total Core & 74.68 & 14.35 \\
\hline Tolerability & 42.41 & 19.06 \\
Environment & 62.61 & 27.50 \\
\hline Total Treatment & 63.01 & 26.56 \\
\hline Total FertiQoL & 71.25 & 13.24
\end{tabular}

Table 2 highlights the FertiQoL mean scores for each core and treatment domains; and mean scores for core, treatment, and total FertiQoL. The highest mean score was for the mind-body part, whereas the lowest score was for tolerability towards treatment.

Table 3: Association between factors and FertiQoL core mean scores (mind-body, emotional, relational, social, and core mean scores) using independent T-test for two

\begin{tabular}{|c|c|c|c|c|c|c|}
\hline Category & Variable & Mind-body & Emotional & Relational & Social & Total Core \\
\hline \multirow[t]{3}{*}{ Sex } & Male & $80.23 \pm 16.05$ & $72.57 \pm 18.42$ & $76.14 \pm 17.73$ & $73.56 \pm 15.05$ & $75.66 \pm 13.53$ \\
\hline & Female & $75.57 \pm 18.37$ & $68.45 \pm 19.23$ & $78.19 \pm 16.76$ & $73.56 \pm 16.27$ & $73.95 \pm 14.91$ \\
\hline & Sig. P-value & $0.009^{* *}$ & $0.028^{*}$ & 0.243 & 1.000 & 0.242 \\
\hline \multirow[t]{3}{*}{ Race } & Malay & $78.69 \pm 16.90$ & $71.33 \pm 18.59$ & $78.70 \pm 16.72$ & $73.82 \pm 16.07$ & $75.64 \pm 14.12$ \\
\hline & Non-Malays & $72.22 \pm 19.60$ & $65.22 \pm 20.12$ & $70.77 \pm 18.03$ & $72.34 \pm 14.15$ & $70.14 \pm 14.64$ \\
\hline & Sig. P-value & $0.012^{*}$ & $0.015^{*}$ & $0.000^{* * *}$ & 0.480 & $0.004^{* *}$ \\
\hline \multirow[t]{3}{*}{ Religious faith } & Islam & $78.81 \pm 16.75$ & $71.31 \pm 18.52$ & $78.94 \pm 16.65$ & $74.02 \pm 15.99$ & $75.77 \pm 14.01$ \\
\hline & Others & $70.97 \pm 20.16$ & $64.75 \pm 20.53$ & $68.78 \pm 17.63$ & $71.16 \pm 14.24$ & $68.92 \pm 14.81$ \\
\hline & Sig. P-value & $0.005^{\star *}$ & $0.012^{*}$ & $0.000^{* * *}$ & 0.188 & $0.000^{* * *}$ \\
\hline \multirow[t]{3}{*}{ Education level } & $\geq$ Degree & $77.52 \pm 17.95$ & $70.71 \pm 18.78$ & $79.56 \pm 16.98$ & $73.67 \pm 16.55$ & $75.37 \pm 14.99$ \\
\hline & $\leq$ Diploma & $77.69 \pm 17.14$ & $69.69 \pm 19.28$ & $74.84 \pm 17.13$ & $73.52 \pm 14.81$ & $73.94 \pm 13.59$ \\
\hline & Sig. P-value & 0.925 & 0.596 & $0.006^{* *}$ & 0.925 & 0.325 \\
\hline \multirow[t]{3}{*}{ Personal Income } & $\geq \mathrm{RM} 3000$ & $79.43 \pm 16.91$ & $72.50 \pm 17.66$ & $78.39 \pm 17.14$ & $75.46 \pm 15.19$ & $76.45 \pm 13.63$ \\
\hline & $<$ RM3000 & $74.79 \pm 18.15$ & $66.95 \pm 20.40$ & $75.73 \pm 17.21$ & $70.75 \pm 16.16$ & $72.06 \pm 15.00$ \\
\hline & Sig. P-value & $0.01^{*}$ & $0.004^{* *}$ & 0.133 & $0.003^{* *}$ & $0.003^{* *}$ \\
\hline \multirow[t]{4}{*}{ Duration of infertility } & $1-2$ years & $78.94 \pm 17.23$ & $71.69 \pm 20.08$ & $82.02 \pm 15.57^{*}$ & $75.00 \pm 14.42$ & $76.91 \pm 14.42$ \\
\hline & $2-5$ years & $78.00 \pm 18.06$ & $70.08 \pm 18.34$ & $77.00 \pm 16.08$ & $73.64 \pm 15.22$ & $74.68 \pm 13.42$ \\
\hline & $>5$ years & $76.34 \pm 17.20$ & $69.64 \pm 19.70$ & $75.57 \pm 18.82^{*}$ & $72.41 \pm 17.05$ & $73.49 \pm 15.50$ \\
\hline & Sig. P-value & $>0.05$ & $>0.05$ & $0.030^{*}$ & $>0.05$ & $>0.05$ \\
\hline \multirow{3}{*}{$\begin{array}{l}\text { Frequency of sexual } \\
\text { activity with partner } \\
\text { per week }\end{array}$} & $\geq 3$ times & $78.79 \pm 14.69$ & $71.02 \pm 14.41$ & $80.23 \pm 15.57$ & $74.84 \pm 13.72$ & $76.22 \pm 10.88$ \\
\hline & $<3$ times & $77.40 \pm 18.86$ & $70.10 \pm 20.85$ & $76.17 \pm 17.38$ & $73.30 \pm 16.37$ & $74.24 \pm 15.55$ \\
\hline & Sig. P-value & 0.460 & 0.649 & $0.025^{*}$ & 0.328 & 0.147 \\
\hline Participant general & Good & $78.98 \pm 16.89$ & $71.05 \pm 18.37$ & $78.23 \pm 16.96$ & $73.69 \pm 15.59$ & $75.49 \pm 13.86$ \\
\hline
\end{tabular}




\begin{tabular}{|c|c|c|c|c|c|c|}
\hline $\begin{array}{l}\text { health perception } \\
\text { question }\end{array}$ & $\begin{array}{l}\text { Poor } \\
\text { Sig. P-value }\end{array}$ & $\begin{array}{l}71.35 \pm 19.23 \\
0.000^{* \star *}\end{array}$ & $\begin{array}{l}66.78 \pm 21.40 \\
0.085\end{array}$ & $\begin{array}{l}73.61 \pm 17.65 \\
0.046^{*}\end{array}$ & $\begin{array}{l}72.86 \pm 16.56 \\
0.687\end{array}$ & $\begin{array}{l}71.15 \pm 16.04 \\
0.020^{*}\end{array}$ \\
\hline Participant general & Good & $79.32 \pm 17.36$ & $71.33 \pm 18.47$ & $78.68 \pm 17.43$ & $75.03 \pm 14.91$ & $76.09 \pm 14.06$ \\
\hline well-being & Poor & $72.34 \pm 17.27$ & $66.92 \pm 20.27$ & $73.15 \pm 15.85$ & $69.24 \pm 17.50$ & $70.42 \pm 14.64$ \\
\hline perception question & Sig. P-value & $0.000 * * *$ & 0.060 & $0.006^{* *}$ & $0.004^{* *}$ & $0.000^{* * *}$ \\
\hline
\end{tabular}

Null hypothesis $\left(\mathrm{H}_{0}\right)$ states that there is no difference between the variables and Alternative hypothesis (if $P$-value is significant) states that there is a difference between the variables. $\left({ }^{*}<0.05,{ }^{* *}<0.01,{ }^{* * *}<0.001\right)$

Table 3 revealed the significant associations between the factors and the individual domains. For the mind-body, higher mean QoL scores were associated with male, Islamic faith, and higher income. For the emotional, higher mean QoL scores were associated with male, Malays, Islamic faith, and frequency of sexual activity. For the relational, higher mean QoL scores were associated with Malays, Islamic faith, and higher education level. For the social, higher mean QoL scores were associated with higher income. For the total core FertiQoL, higher mean scores were associated with Malays, Islamic faith, and higher income. There were no significant associations for smoking status, children, duration of infertility, previous appointments with infertility doctors, and previous procedures. For the two perceptive questions, the general health question was significantly associated with the mind-body and relational domain. The general well-being question was significantly associated with the mind-body, relational, and social domains.

\begin{tabular}{|c|c|c|c|c|c|c|c|}
\hline $\begin{array}{l}\text { SLR } \\
\text { Variable }\end{array}$ & $B$ & $95 \% \mathrm{Cl}$ & Beta & $\mathrm{T}$ & \multicolumn{3}{|l|}{$p$} \\
\hline (Constant) & 66.464 & [63.370 69.558] & & 42.236 & 0.000 & & \\
\hline Malay & -2.868 & {$[2.396$ 9.209] } & 0.167 & 3.349 & 0.001 & & \\
\hline (Constant) & 65.418 & [62.195 68.640] & & 101.446 & 0.000 & & \\
\hline Islam & 6.943 & {$\left[\begin{array}{lll}3.427 & 10.459\end{array}\right]$} & 0.192 & 3.883 & 0.000 & & \\
\hline (Constant) & 67.502 & {$[64.28170 .723]$} & & 41.207 & 0.000 & & \\
\hline Income & 2.042 & 0.4293 .655 & 0.127 & 2.490 & 0.013 & & \\
\hline (Constant) & 60.927 & {$[55.276$ 66.577] } & & 21.200 & 0.000 & & \\
\hline $\begin{array}{l}\text { General well- } \\
\text { being }\end{array}$ & 3.665 & [1.717 5.613] & 0.185 & 3.699 & 0.000 & & \\
\hline \multicolumn{8}{|l|}{ MLR } \\
\hline & \multicolumn{2}{|c|}{ Unstandardized coefficient } & \multicolumn{2}{|c|}{ Std coefficient } & & \multicolumn{2}{|l|}{ Collinearity } \\
\hline & $B$ & Std Error & Beta & $\mathrm{T}$ & Sig & Tolerance & $\mathrm{V} / \mathrm{F}$ \\
\hline (Constant) & 51.105 & 3.528 & & 14.484 & 0.000 & & \\
\hline${ }^{*}$ Religion (Islam) & 6.867 & 1.790 & 0.191 & 3.836 & 0.000 & 0.989 & 1.011 \\
\hline $\begin{array}{l}\text { General well } \\
\text { being }\end{array}$ & 3.612 & 0.989 & 0.182 & 3.653 & 0.000 & 0.985 & 1.015 \\
\hline Income & 2.295 & 0.796 & 0.143 & 2.884 & 0.004 & 0.994 & 1.006 \\
\hline
\end{tabular}

Table 4 presents the predictors for the factors that can significantly affect QoL. In simple regression, the factors that predicted better QoL were Malays, Islamic faith, higher income, and increased general well-being scores. For the multiple linear regression, there was strong collinearity between Malays and Islamic faith. Therefore, the final model shows predictors were Islamic faith, a good perception of general well-being, and higher income. Those with Islamic faith have a 6.867 prediction of higher QoL than those from other religions. Those who reported higher scores in their perception of general well-being have a 3.612 prediction of higher QoL. Those with a unit of higher income have a 2.295 prediction of higher QoL.

\subsection{Discussion}

This study highlighted that infertile individuals in Malaysia tend to have an excellent overall quality of life (QoL). The core mean scores for the Malaysian FertiQoL of 74.68 (SD 14.35) is comparable to the Dutch FertiQoL 70.80 (SD 13.90) and Indonesian FertiQoL 70.05 (SD 13.36) (Aarts et al., 2011; Priangga et al., 2016). The Malaysian core FertiQoL scores are much higher in comparison to the FertiQoL study in Pakistan 52.17 (SD 13.13) and Taiwan 55.12 (SD 13.72) (Karabulut et al., 2013, Hsu et al., 2013). Interestingly, the Malaysian FertiQoL domain scores are closely related to the Indonesian FertiQoL study and specifically in the relational scores with 77.32 (SD 17.20) to 75.19 (SD 15.11) respectively. A possible explanation for this similar finding is the common root language shared between the two populations.

The domain scores within the mind-body and relational were higher in comparison to the social and emotional domains. The explanation is perhaps the social and emotional aspect is more abstract and not easy for participants to express. A study on the emotional expression (EE) of Malaysians shows that culturally, Malaysians are less likely to express negative emotions such as feelings of sadness, anger, discontent, or fear. They are more likely to express themselves with positive emotions such as feeling happy (Wong., 2011). This inherent culture of secrecy and not expressing oneself with negative emotions may be the reason for the lower scores in emotional and social domains. The ability to communicate and share feelings with others is known to be an excellent coping skill that can improve the QoL (Kaliarnta et al., 2011; Galhardo et al., 2013). A review of infertility psychosocial interventions shows that either group interventions or counselling sessions (that include emotional expression) can produce positive effects, and 
some reduction in distress (Boivin et al., 2013). Hence, there is a role for infertility counselling to encourage sharing and expressing negative emotions within a safe environment to improve the QoL.

The study found that men have higher scores in the mind-body and emotional domain, but there was no significant difference in overall QoL. Many published gender and dyad studies have identified and predicted gender differences in QoL among those with fertility problems. This study supports the previous findings that both sexes are psychologically and emotionally affected by infertility (Slade et al., 2007; Edelmann and Connolly, 2010; Omu and Omu, 2010). This FertiQoL study also agreed with previous studies that women tended to have lower QoL in the emotional and mind-body domain as compared to men (Hsu et al., 2013; Haica et al., 2013; Bose et al., 2017; Desai and Gundabattula.,2019). Therefore, the conclusion is that infertility affects the QoL of both genders. However, women are more affected, physically, and emotionally. Studies also show that both men and women benefit from infertility counselling (Boivin., 2003).

This study identified that race and religion affect QoL, specifically in the mind-body, emotional, and relational domains. The Malay race and Islamic faith have higher QoL compared to other races and those from other religions. Since the Malays are predominantly Muslim, we can conclude that this result is harmonious. This is surprising because other infertility studies within Muslim communities have depicted a pro-natal view that emphasizes on marriage and parenthood. Such beliefs harm the QoL among those with infertility problems (Ombelet et al., 2006; Omu and Omu, 2010; Obeidat et al., 2014). Race and religious faith are influenced by socio-cultural context, which includes widely held ideas, beliefs, practices, and expectations (Greil et al., 2010). The socio-cultural context has a significant influence on infertility since infertility relates to an experience of unintended childlessness and the society's view upon it (Slade et al., 2007; Greil et al., 2010). In a cross-cultural FertiQoL study involving three countries, the Jordanian group was found to be pro-natal and have lower QoL scores compared to their German and Hungarian counterparts (Sexty et al., 2016). Cultures where there is the expectation of married couples to have children, or the emphasis on women to 'prove' their fertility can lead to anxiety and distress (Greil et al, 2011). The possible explanation from this study is the cultural emphasis on the spiritual aspect of the Islamic faith can provide comfort to those with a fertility problem. This requires further exploration, perhaps in the form of a qualitative study to identify specific ideas or practices unique to this population.

This study showed that income also influenced the QoL, especially in the mind-body, emotional, and social domains. This is like other studies that showed economic disparity as a known factor for stress and anxiety among infertile individuals. The inequalities of health and treatment can contribute to low QoL (Bitler and Schmidt, 2006; Bell et al., 2010).

Finally, the study formulated a positive prediction score for QoL that included religious faith, higher income, and a perception question on general well-being. On the surface, race or religion are non-modifiable factors. However, the cultural influences, positive beliefs, and spiritual practices may improve the QoL in infertile individuals. Exploring and identifying these factors may assist in the formulation of effective infertility counselling interventions.

\subsection{Strength And Limitations}

The strength of the study is in its sampling because data collection was from four well known public infertility centres. These centres were accessible and affordable to the public. The limitations include patients recruited were at various stages of their infertility treatment, such as the first appointment, follow up, or already on fertility treatment. The study does not represent those with infertility problems that have not registered in any infertility centres and are 'suffering in silence'. Another limitation of the study was the representation of most participants were from one ethnic and religious group. Therefore, for the data analysis, ethnic groups and religion had to be re-coded and put under two categories comparing Malay versus others and Islamic faith versus other religions which may skew the results.

The Malaysian FertiQoL used was translated by the original developers from the English language. The researchers provided a report to the developers on any feedback and discrepancies in the participant's understanding of the FertiQoL items. However, the researchers did not make any changes to the FertiQoL questionnaire.

\subsection{Conclusion}

Infertile individuals in Malaysia have high core FertiQoL scores. Being Malay with the Islamic faith, and having higher income are positive predictors for QoL. It is possible to use the general question of well-being as a short screening tool to predict good QoL among infertile individuals.

\section{Acknowledgements}

The authors would like to acknowledge the research team members, Dr Zaliha Ismail, Dr Abdul Kadir Abdul Karim, Dr Muhd Azrai $\mathrm{Abu}$, and Chin Ken Lee, for their contribution to the study. The authors would like to thank Dr Goh Pik Pin from Clinical Research Centre, Hospital Kuala Lumpur for her supervision and guidance as well as Fong Ai Hsing (UKM), Siti Khadijah Mohd Bustaman (IIUM) and all clinic staff in LPPKN for their cooperation and assistance towards the study. Also, we would like to acknowledge the funding of the LESTARI grant from IRMI, Universiti Teknologi MARA. 


\section{References}

Aarts J.W, Van Empel I.W.H, Boivin J, Nelen W.L (2011). Relationship between quality of life and distress in infertility: a validation study of the Dutch FertiQoL. Human Reproduction. 25(5), 1-7

Ariffin F, Daud S, Ismail Z, Ramli R, Zainuddin A.A (2020). Language and Cross-cultural influences in the Psychometric Evaluation of the Malaysian FertiQoL. Malaysian Journal of Medical Health Sciences. 16(2), 157-163.

Bell A.V (2010). Beyond (financial) accessibility: inequalities within the medicalization of infertility. Sociology of Health \& Illness, 32(4), 631-646

Bitler M, Schmidt L (2006). Health disparities and infertility: impacts of state-level insurance mandates. Fertility and Sterility, 85(4), 858-865

Boivin J (2003). A review of psychosocial interventions in infertility. Social Science \& Medicine 57(12), 2325-2341.

Boivin J, Bunting L (2007). Decision-making about seeking medical advice in an internet sample of women trying to get pregnant. Human reproduction. 22(6), 16621668 .

Boivin J. Bunting L. Collins J.A. Nygren K.G (2007). International estimates of infertility prevalence and treatment-seeking: potential need and demand for infertility medical care. Human reproduction. 22(6), 1506-1512.

Boivin J, Takefman J, Braverman A (2011). The Fertility Quality of Life (FertiQoL) tool: development and general psychometric properties. Human reproduction. 26(8), 2084-2091.

Bose S, Roy B (2017). Fertility related Quality of Life in primary infertile couples: A comparative study from Eastern India. The International Journal of Indian Psychology. 5(1), 1-19.

Daniluk J.C, Frances-fischer J.E. (2009). A sensitive way to address your infertile patients' concerns. Infertility. Sexuality Reproduction and Menopause. 7(1), 3-7

Desai H.J and Gundabattula S.R. (2019). Quality of life in Indian women with Fertility Problems as Assessed by the FertiQoL questionnaire: a single-center crosssectional study. Journal of Psychosomatic Obstetrics and Gynaecology. 40(1), 82-87.

Donarelli Z, Lo Coco G, Gullo S, Salerno L, Marino A, Sammartano F, Allegra A (2016). The Fertility Quality of life questionnaire (FertiQoL) Relational subscale: psychometric properties and discriminant validity across gender. Human Reproduction. 31(9), 2061-2071.

Edelmann R.J, Connolly K (2010). Gender differences in response to infertility and infertility investigations: real or illusory. British journal of health psychology. 5(4), 365-375.

Galhardo A, Cunha M, Pinto-Gouveia J (2013). Mindfulness-based program for infertility: an efficacy study. Fertility and Sterility. 100(4), $1059-1067$.

Greil A.L, Slauson-Blevins K, McQuillan J (2010). The experience of infertility: A review of recent literature. Sociology of Health \& IIIness. 32(1), 140-162.

Greil A.L, Slauson-Blevins K, McQuillan J (2011). The social construction of infertility. Sociology Compass. 5(8), 736-746.

Haica C.C. Gender differences in Quality of Life, Intensity of dysfunctional attitudes, unconditional self-acceptance, emotional distress, and dyadic adjustment of infertile couples. Procedia - Social and Behavioural Sciences. 78, 506-510

Hanafiah H, Jemain A (2013, March). Impact of women's participation in economic development on fertility in peninsular Malaysia. 4th International conference on business and economic research (4th ICBER). Bandung, Indonesia.

Hsu P-Y, Lin M-W, Hwang J-L, Lee M-S, Wu M-H (2013). The fertility quality of life (FertiQoL) questionnaire in Taiwanese infertile coupe. Taiwanese Journal of Obstetrics \& Gynaecology. 52(2), 204-209.

Kaliarnta S, Nihlén-Fahlquist J, Roeser S (2011). Emotions and Ethical considerations of women undergoing IVF-treatments. HEC Forum. 23, 281-293

Karabulut A, Özkan S, Oguz N (2013). Predictors of fertility quality of life (FertiQoL) in infertile women: analysis of confounding factors. European Journal of Obstetrics \& Gynecology and Reproductive Biology. 170(1), 193-197.

Maroufizadeh S, Ghaheri A, Amini P, Samani R.O (2017). Psychometric properties of the Fertility Quality of Life instrument in infertile Iranian women. International Journal of Fertility \& Sterility. 10(4), 371-379

Obeidat H.M, Hamlan A.M, Callister L.C (2014). Missing motherhood: Jordanian women's experiences with infertility. Advances in Psychiatry. Article ID 241075.

Ombelet W, Cooke I, Dyer S, Serour G, Devroey P (2008). Infertility and the provision of infertility medical services in developing countries. Human Reproduction Update. 14(6), 605-621.

Omu F.E, Omu A.E (2010). An emotional reaction to the diagnosis of infertility in Kuwait and successful clients' perception of nurses' role during treatment. BMC Nursing. 9(5)

Priangga M.D, Pratama G, Maidarti M, Harzif A.K, Wiweko B (2016). Validity of the Fertility Quality of Life (FertiQoL) questionnaire in Indonesian infertile women in ASPIRE conference proceedings. The $6^{\text {th }}$ Congress of the Asia Pacific Initiative on Reproduction, KnE Medicine, $202-206$

Sexty R.E, Hamadneh J, Rosner S et al. (2016). Cross-cultural comparison of fertility specific quality of life in German, Hungarian, and Jordanian couples attending a Fertility Center. Health Quality of Life Outcomes. 14-27. 
Slade P, Neill C.O, Simpson A.J, Lashen H (2007). The relationship between perceived stigma, disclosure patterns, support, and distress in new attendees at an infertility clinic. Human reproduction. 22(8), 2309-2317.

Van den Broeck U, Emery M, Wischmann T, Thorn P (2010). Counseling in infertility: individual, couple, and group interventions. Patient Education Counselling. 81(3) 422-8.

Wischmann T, Korge K, Scherg H, Strowitzki T, Verres R (2012). A 10-year follow-up study of psychosocial factors affecting couples after infertility treatment. Human reproduction. 27(11), 3226-3232.

Wong N.L, Kuang C.H, Khemlani D (2014). Emotions: An insight into how Malaysians express themselves. Semantic scholar; Available at https://www.semanticscholar.org/paper/Emotions-\%3A-An-insight-into-how-Malaysians-express-1-Ling-Hei/1bcfa21cace3be276d71632bd3cf42c52d25d808 